Herzschr Elektrophys 2016 $27: 412$

DOI 10.1007/s00399-016-0429-3

Published online: 6 October 2016

๑) Springer-Verlag Berlin Heidelberg 2016

CrossMark

\section{Original publication}

Sorleto M, Wuttig H, Aydilek E, Wiemer M (2016) Missmanagement im

Arrhythmieerkennungsalgorithmus der LifeVest ${ }^{\circledR}$ mit konsekutivem letalen Verlauf. Herzschr Elektrophys 27:57-62

\section{Dear Editor,}

I read with interest the case report from Sorleto et al. about using a wearable cardioverter defibrillator (WCD) in a patient, although this patient may have been sicker than most because the VT/VF rapidly deteriorates into loose undulating waves. The authors do not state the detection threshold but the rate drops below $150 \mathrm{BPM}(2.5 \mathrm{~Hz})$ then fades into asystole. The deterioration is consistent with a terminal event that is likely resistant to shock therapy. The authors conclude that the lack of treatment by the WCD represents that an undersensing episode occurred.

However, the WCD operated as currently designed. Modern implantable devices are rarely programmed for VF detection below $320 \mathrm{~ms}$ (188 BPM) of at least $400 \mathrm{~ms}$ (150 BPM). In case of an ICD (implantable cardioverter/defibrillator) with a cardiac signal of a similar appearance, the possibility of undersensing is highly likely and has been reported in recent publications [1]. Studies of ICDs show mortality improvements at higher detection rates, probably such a programming would have prevented this patient's treatment. Despite ICD study mortality benefit, unique cases like this patient are tragic and not preventable with current technology.

Johannes Sperzel

Kardiologie-Elektrophysiologie, Kerckhoff-Klinik, Bad Nauheim, Deutschland

\title{
Wearable cardioverter defibrillator
}

Use of surface electrodes require the WCD algorithm to handle noise mimicking VT/VF. Compared with an ICD a WCD is beneficial by continuously evaluating the cardiac signal and allowing conscious patients to respond to alarms. While alternate programming that could have resulted in treatment for this patient is possible, one must be careful of unintended consequences. For example, shortening time to shock or lowering the detection rate could lead to an increase number of inappropriate shocks. Conversely, raising the detection rates could delay or prevent appropriate therapy.

It is important to provide the larger picture of WCD performance. Several studies [2, 3] have shown excellent detection of VT/VF. This particular case, although tragic, reminds us that sensitivity can never be $100 \%$ if reasonable specificity is to be achieved.

Sincerely,

Johannes Sperzel

\section{Corresponding address}

\section{Priv.-Doz. Dr. J.Sperzel}

Kardiologie-Elektrophysiologie, KerckhoffKlinik

Benekestr. 2-8, 61231 Bad Nauheim,

Deutschland

j.sperzel@kerckhoff-klinik.de

Conflict of interest. J. Sperzel states that there are no conflicts of interest.

\section{References}

1. Montgomery et al (2016) Sudden cardiac death despite a functional defibrillator. J Cardiovasc Electrophysiol 27:120-124
2. Chung et al (2010) Aggregate national experience with the wearable cardioverter-defibrillator: event rates, compliance, and survival. J Am Coll Cardiol 56:194-203

3. Kutyifaetal (2015) Use of the wearable cardioverter defibrillator in high-risk cardiac patients: data from the prospective registry of patients using the wearable cardioverter defibrillator (WEARIT-II registry). Circulation 132(17):1613-1619 